\title{
REVIEW ON AZADIRACHTA INDICA LEAVES RELATED TO ITS ACTION AGAINST ACNE VULGARIS
}

\author{
Samreen Khan ${ }^{1}$, Yasmeen Shamsi ${ }^{2 *}$, Umar Jahangir ${ }^{3}$ and Mukesh Manjhi ${ }^{4}$ \\ ${ }^{1,2}$ Department of Moalajat, Hayat Unani Medical College \& Research Centre, Lucknow, India \\ ${ }^{3}$ Department of Jild wa Tazeeniyat, School of Unani Medical Education \& Research, Jamia Hamdard, New Delhi, India \\ ${ }^{4}$ Department of Dermatology, Hamdard Institute of Medical Science and Research, New Delhi, India
}

\section{Review Paper}

Received: 12.05.2021

Revised: 18.05.2021

Accepted: 07.06.2021

\begin{abstract}
Acne vulgaris is a common dermatological disease with huge psychological burden. The pathophysiology of acne include various factors among them bacterial colonisation and inflammation are supreme culprit in the causation of disease. The leaves of Azadirachta indica possesses both antibacterial and anti-inflammatory actions against the causative micro-organism which supports the use of Azadirachta indica leaves in traditional system of medicine
\end{abstract}

No. of Pages: 6

References: 63

Keywords: Acne vulgaris, Azadirachta indica, Barg-e-neem, Propionibacterium acnes, anti-inflammatory.

\section{INTRODUCTION}

Acne vulgaris is chronic, often self-limiting inflammatory disease of pilosebaceous unit, manifesting generally in adolescence with pleomorphic lesions like comedones, papules, pustules, nodules and cysts (1). Acne vulgaris globally targets 650 million people or around 9.4\% population, hence making it eighth most prevalent disease worldwide. There is $22 \%$ rise in DALYs (Disability- adjusted life years) in global burden of disease study 2010 due to acne vulgaris since 1990(2).

Although basic cause of acne is unknown; (3) its pathophysiology is based upon several factors, which include excessive sebum production, alteration of the quality of sebum lipids, dysregulation of the hormone microenvironment, neuropeptide interaction, hyperkeratinization, Propionibacterium acnes colonization and inflammation(4)(5)(6).
Propionibacterium acnes and other micro-organisms involved in Pathogenesis

The role of micro-organisms in the pathogenesis of acne vulgaris is commonly associated with inflammatory acne lesion. According to Studies, most common micro-organisms involved in acne vulgaris are Propionibacterium acnes, Staphylococcus epidermidis and Staphylococcus aureus(7).

The Propionibacterium acnes is a Gram-positive anaerobic non-motile, pleomorphic, rod-shaped bacterium which is considered to be skin commensal, commonly resides in sebaceous follicles. The presence of $P$. acnes is beneficial due to its ability to lower the $\mathrm{pH}$ of skin by acidic fermentation of products, thus protecting the follicles against colonization by harmful pathogens (8). The virulence factors involved in Propionibacterium acnes include neuraminidases, sialidases and endo-glycoceramidases (9). The bio-film is also excreted by P. acnes which is gylcocalyx polymer and it contributes to its persistence and immunogenicity (10). It plays significant

*Corresponding author: yshamsi@jamiahamdard.ac.in 
role in the development of inflammatory acne. The bacterial overgrowth can lead to precipitation of innate immune response and, in some cases follicular wall rupture may occurs which initiates host inflammatory reaction. $P$. acnes releases many enzymes, such as proteinases, lipases, hyaluronidases and chemotactic factors(11) and may direct immune reactions by modulation of the T-helper cell (TH1/TH2) response and induction of monocyte-derived dendritic cell maturation(12).

Staphylococcus epidermidis is a Gram-negative aerobic bacterium, also considered as skin commensal and colonizes various areas of the skin but sometimes it acts as an opportunistic micro-organism by breaching the skin surface and entering the bloodstream (13). The lipases, fatty acid modifying enzyme, polysaccharide intercellular adhesion (PIA), and poly-glutamic acid are the virulence factors in Staphylococcus epidermidis(14).

Staphylococcus aureus, is an opportunistic Gram-positive pathogen, implicated in pathogenesis of acne vulgaris and is associated with pus from acne. Their co-existence with other microbes in acne lesions has been reported (15) (16). The virulence factors of $S$. aureus involved in the pathogenesis of acne are adhesins, fibronectin binding protein, proteases, lipases, and hyaluronidases (17). Presence of S. aureus in the oropharnx and nose are higher in patients with acne than controls without acne(18)(9).

All these microorganisms implicated, have been isolated from the pustular lesions of acne vulgaris. In a study conducted by Yousif et al., 27.08\% Staphylococcus epidermidis (aerobic bacterium) and 13.02\% Propionibacterium acnes (anaerobic bacteria) were isolated from inflammed and discharging pus from 160 acne patients(19).Another study identified the involved pathogen from samples of 80 patients and out of $71.24 \%$ isolatedaerobic organisms $54.38 \%$ were Staphylococcus epidermidis and among 26.25\% isolated anaerobes 57.14\% were Propionibacterium acnes (20).Various other studies have demonstrated the presence of $S$. aureus in pustular lesions of acne and sensitivity test has shown multiple antibiotic resistance of the organism(21)(22) (23). In another study five strains of $S$. aureus and 11 strains of $S$. epidermidis were isolated from 25 samples from acne patients (7). The results of all these mentioned studies imply that these three micro-organisms viz., Propionibacerium acnes, Staphylococcus epidermidis and Staphylococcus aureus, are commonly involved in acne infection.

\section{Inflammation}

The role of P. acnes in the aetiology of inflammatory acne has been recognized for more than a century. It stimulates host innate immune response with activation of Toll-like receptors (TLRs) which are in response against pathogen.
TLRs are present on keratinocytes, monocytes/macrophages, langerhans cells, $\mathrm{T}$ and $\mathrm{B}$ lymphocytes, mast cells and endothelial cells. TLR activation further leads to activation of nuclear factors, which promotes gene expression responsible for production of cytokines, chemokines and adhesion molecules. P. acnes activates TLR-2, resulting in increased levels of IL-8, IL-12, tumour necrosis factor-(alpha), and IL1 (beta) (24) (25) (26). In cultured human epidermal keratinocytes, TLRs, activation also induces human bdefensin-2 (and IL-8) expressions which are a family of antimicrobial peptides produced in the skin against microbial infection and are implicated in clinically inflammatory acne lesion formation. The properties of b-defensins include modification of cell migration and maturation, induction of cytokines, and chemo-attraction of immune-competent cells (27)(28).

Recent data also suggests that inflammatory events in acne vulgaris could occur even before the microcomedones formation, which is supported by the fact that uninvolved skin from acne patients contains elevated levels of CD3+ and CD4+ T cells in the perifollicular and papillary dermis and increased macrophage numbers similar to those seen in papules(29).

\section{Studies of Azadirachta indica leaves related to its action against Acne vulgaris}

\section{Anti-bacterial activity of Azadirachta indica against $\mathbf{P}$. acne}

Barg-e-Neem (Azadirachta indica) possesses antibacterial action against $P$. Acnes (Acne causing bacteria). In an in-vitro study aqueous, ethanolic and petroleum ether extract have exhibited antibacterial action .The zone of inhibition of Azadirachta indica was14 mm for $5 \mathrm{mg} /$ disc, $14 \mathrm{~mm}$ for 7 $\mathrm{mg} / \mathrm{disc}, 15 \mathrm{~mm}$ for $10 \mathrm{mg} /$ disc in aqueous extract. In ethanolic extract the zone of inhibition was $14 \mathrm{~mm}$ for $5 \mathrm{mg} /$ disc, $15 \mathrm{~mm}$ for $7 \mathrm{mg} /$ disc, $15 \mathrm{~mm}$ for $10 \mathrm{mg} /$ disc. The zone of inhibition for ethanolic extract was $9 \mathrm{~mm}$ for $5 \mathrm{mg} / \mathrm{disc}, 12$ $\mathrm{mm}$ for $7 \mathrm{mg} /$ disc, $15 \mathrm{~mm}$ for $10 \mathrm{mg} /$ disc in Petroleum ether extract. Thus, results of the study revealed that Barg-e-Neem has potential antibacterial activity and both aqueous and ethanolic extract are equally significant against Propionibacterium acnes(30).

Anti-bacterial activity of Azadirachta indica against
Staphylococcus aureus and Staphylococcus epidermidis
In an in-vitro study antibacterial activity of ethanolic and
methanolic extract of Azadirachta indica leaves was assessed
against various opportunistic bacterial strains including
Staphylococcus aureus and Staphylococcus epidermidis. The
minimum inhibitory concentration (MIC) of methanlic
extract of $50 \mathrm{gm}$ of Azadirachta indica leaves against S.
aureus was $12 \mathrm{~mm}$ and against S. eidermidis was $10 \mathrm{~mm}$.
Similarly ethanolic extract of $50 \mathrm{~g}$ of Azadirachta indica 
leaves has $11 \mathrm{~mm}$ and $18 \mathrm{~mm}$ MIC against $S$. aureus and $S$. epidermidis respectively. Thus, indicating its great potential against these opportunist infections which also play role in pathogenesis of acne(31).

Topical anti-inflammatory activity of Azadirachta indica Barg-e-Neem (Azadirachta indica) also possesses topical anti-inflammatory action. The study was conducted to assess to anti-inflammatory activity by inducing skin oedema test using turpentine oil. The percentage of inhibition of the inflammation was $45.23 \%$ for petroleum ether extract 26.34\% for chloroform extract and 9.16\% for ethyl alcohol. All extracts, except the ethyl alcohol extract, showed significant inhibition of the inflammation compared to control. The study concluded that petroleum ether extract has the maximum capability to inhibit the process of inflammation, and it has comparable anti-inflammatory activity of diclofenac gel (49.82\%), the drug used as reference(32).

In an in-vitro study conducted by Kaur et al., rat peritoneal macrophage exposure to nimbidin inhibited phagocytosis and phorbol-12-myristate-13-acetate (PMA) stimulated respiratory burst in these cells. It also inhibited nitric oxide (NO) and prostaglandin E2 (PGE2) production in lipopolysaccharide (LPS) stimulated macrophages but interleukin 1 (IL-1) inhibited mildly. In addition, nimbidin led to degranulation of neutrophilic lysozomes and release of myeloperoxidase, beta-glucuronidase and lysozyme. Thus, the results concluded that nimbidin suppresses the functions of macrophages and neutrophils relevant to inflammation (33).

\section{Antioxidant activity of Azadirachta indica}

The antioxidant activity was evaluated in young flowers and leaves. The parameter of oxidative stress, malondialdehyde (MDA), was reduced by $46.0 \%$ in flower extract and $50.6 \%$ in leaf-based extracts.(34)

\section{Skin renewal activity}

The effect of various extract of Azadirachta indica was assessed on skin renewal rate. The maximum increase in skin renewal was $27.5 \%$ shown by hydro-alcoholic macerate extract followed by hydro-alcoholic $23.75 \%$ and alcohol extract $23.12 \%(35)$.

\section{CONCLUSION}

The potentional of the leaves of Azadirachta indica is evident through the above mentioned preclinical data which supports its action against the pathophysiology of acne vulgaris. Thus the use of Azadirachta indica leaves in traditional medicine is quite close to antibacterial and anti-inflammatory approach of contemporary medicine.

\section{BIBLIOGRAPHY}

1. Vaishampayan, S S and Tutakne, MA. Acne, Rosacea and perioral dermatitis. [ed.] R G Valia and A R Valia. 3. s.l. : IADVL textbook of dermatology, 2008. pp. 439-50.

2. The Global Burden of Skin Disease in 2010: An Analysis of the Prevalence and Impact of Skin condition. Hay, Roderick J., et al. 2014. Journal of Investigative Dermatology. Vol. 134, pp. 1527-1534.

3. Khanna, Neena. Illustrated synopsis of Dermatology and sexually transmitted Diseases. 5. Delhi : s.n., 2015. pp. 110-120.

4. An update on the role of the sebaceous gland in the pathogenesis of acne. Makrantonaki, Evgenia, Ganceviciene, Ruta and Zouboulis, Christos. 1, 2011, Dermatoendocrinol, Vol. 3, pp.41-49.

5. Schachner, L.A. and Hansen, R.C., [ed.]. Pediatric Dermatology. 4. Philadelphia : Elsevier, 2011. pp. 827848. Vol. 1.

6. Rook, Arthur, Wilkinson, Darrell and Ebling, John. Rook's Textbook of Dermatology. [ed.] Christopher E. M. Christopher E. M. Griffiths, et al. Ninth. West Sussex, UK : John Wiley \& Sons, Ltd, 2016. p. 90.1. Vol. 2.

7. Antibiotic Sensitivity of Staphylococcus aureus and Staphylococcus epidermidis Isolated from Acne Patients. Khan, Ashfia Fatima, et al. 2, 2015, Bangladesh Pharmaceutical Journal, Vol. 18, pp. 121125.

8. Skin microbiota: a source of disease or defence? Cogen, AL, Nizet, V and Gallo, RL. 2008, Br J Dermatol, Vol. 158, pp. 442-455.

9. Insights in the pathogenic potential of Propionibacterium acnes from its complete genome. Brüggemann, H. 2, 2005, Semin Cutan Med Surg, Vol. 24, pp. 67-72.

10. Genome sequence of Propionibacterium acnes reveals immunogenic and surfaceassociated genes confirming existence of the acne biofilm. Burkhart, $\mathrm{CN}$ and Burkhart, CG. 7, 2006, Int J Dermatol. Vol. 45, p. 872.

11. Vaccine therapy for P.acnes-associated diseases. Nakatsuji, T, Rasochova, L and Huang, CM. 3, 2008, Infect Disord Drug Targets, Vol. 8, pp. 160-165.

12. The effect of Propionibacterium acnes on maturation of dendritic cells derived from acne patients' peripherial blood mononuclear cells. Michalak-Stoma, A, et al. 4, 2008, Folia Histochem Cytobiol. Vol. 46, pp. 535-539.

13. Staphylococci: colonizers and pathogens of human skin. Coates, R, Moran, J and Horsburgh, MJ. 2014. Future Microbiol. Vol. 2014, pp. 75-91. 
14. Genome-based analysis of virulence genes in a nonbiofilm-forming Staphylococcus epidermidis strain (ATCC 12228). Zhang, YQ, et al. 6, 2003, Mol Microbiol, Vol. 49, pp. 1577-93.

15. Staphylococcus epidermidis in human skin microbiome associated with acne: a cause of disease or defence? Pathak, R, et al. 2013, Res J Biotechnol, Vol. 8, pp. 7882.

16. Staphylococcus aureus: new evidence for intracellular persistence. Garzoni, C and Kelley, WL. 2009, Trends Microbiol, Vol. 17, pp. 59-65.

17. Lipase, protease, and biofilm as the major virulence factors in staphylococci isolated from acne lesions. Saising, J, et al. 2012, Biosci Trends, Vol. 6, pp. 160-64.

18. A systematic review and meta-analysis on Staphylococcus aureus carriage in psoriasis, acne and rosacea. Totté, J. E. E., et al. 2016. Eur J Clin Microbiol Infect Dis, Vol. 35, pp. 1069-1077.

19. Isolation and identification of microorganisms in acne patients. Yousif, Niyan Innam Muhammed and Dabbagh, Rassool A. 2, 2016. Zanco J. Med. Sci, Vol. 20, pp. 1330-36.

20. Bacteriology of Acne. Srikanth, Maddu, et al. 19, 2015, Journal of Evolution of Medical and Dental Sciences. Vol. 4, pp. 3267-74.

21. Studies on Staphylococcus aureus Isolated from Pimples. Adetutu, Ajayi Adesola, et al. 7, 2017, Pak. J. Biol. Sci, Vol. 20, pp. 350-354.

22. The effect of hand treatments on Staphylococcus aureus: A normal flora of the human palms. Ajayi, A.A., Aiyedun, B.T. and Olasehinde, G.I. 2013, Adv. Biosci. Bioeng., Vol. 1, pp. 44-53.

23. Antibiotics resistance and susceptibility pattern of a strain of Staphylococus aureus associated with acne. Adejuwon, A.O., et al. 2010, Int. J. Med. Med. Sci., Vol. 2, pp. 277-280.

24. Toll-like receptos in the skin. Miller, LS. 2008, Adv Dermatol, Vol. 24, pp. 71-87.

25. The role of toll-like receptors in the pathogenesis and treatment of dermatological disease. McInturff, JE, Modlin, RL and Kim, J. 1, 2005, J Invest Dermatol, Vol. 125, pp. 1-8.

26. Activation of Toll-Like Receptor 2 in Acne Triggers Inflammatory Cytokine Responses. Kim, Jenny, et al. 2002, The Journal of Immunology. Vol. 169, pp. 15351541.

27. Distinct strains of Propionibacterium acnes induce selective human beta-defensin-2 and interleukin-8 expression in human keratinocytes through toll-like receptors. Nagy, I, et al. 5, 2005. J Invest Dermatol, Vol. 124, pp. 931-8.

28. Antimicrobial peptides: the ancient arm of the human immune system. Wiesner, J and Vilcinskas, A. 5, 2010, Virulence, Vol. 1, pp. 440-64.

29. The Role of Inflammation in the Pathology of Acne. Jeremy, AH, et al. 1, 2003. J Invest Dermatol. Vol. 121, pp. 20-27.

30. Antibacterial activity of certain medicinal plants against Acne-inducing bacteria. Balalkrishnan, K. P., et al. 3, 2011. International Journal of Pharma and Bio Sciences, Vol. 2, pp. B476-B481.

31. Antibacterial Study of Neempatra Extract On Escherichia coli, Pseudomonas aeuroginosa, Corynebacteria, Staphylococcus aureus and Staphylococcus epidermidis- An In Vitro Study. Neeta, Khairnar and Pankaj, Musale. 3, 2016. International Journal of Ayurvedic and Herbal Medicine, Vol. 6, pp. 2248-2251.

32. Evaluation of Topical Antiinflammatory Effect Of Azadirachta Indica Leaf Extract. Yadav, K.C.Haritha and Rao, Y. Venkata. 5, 2012, International Research Journal of Pharmaceutical and Applied Sciences, Vol. 2, pp. 60-64.

33. Nimbdin suppresses functions of macrophages and neutrophils: relevance to its anti-inflammatory mechanisms. Kaur, G, Alam, Sarwar and Athar, M. 4, 2004, Phytotherapy Research, Vol. 18, pp. 419-424.

34. Antioxidant activity of Siamese neem tree. Sithisam, $\mathbf{P}$, Supabphol, R and Gritsanapan, W. 2005, ethnopharmacol journal, Vol. 99, pp. 109-112.

35. Skin renewal effect of different extracts of leaves of Azadirachta indica. Kamlesh, W, Lakhotiya, C L and Umeshkar, M J. 4, 2009, International Journal of Pharma Tech Research, Vol. 1, pp. 1350-53.

36. Pharmacology1Antimicrobial activity of Azadirachta Indica(neem) leaf, bark and seed extracts. Raja Ratna Reddy, Y, et al. 1, 2013, International Journal of Research in Phytochemistry \& Pharmacology, Vol. 3, pp. 1-4.

37. Antibacterial Activity of Neem (Azadirachta indica) Leaves on Vibrio spp. Isolated from Cultured Shrimp. Banerjee, Sanjoy, et al. 2, 2013, Asian Journal of Animal and Veterinary Advances, Vol. 8, pp. 355-361.

38. Antimicrobial Activity of Medicinal plants Azdirachta indica A. Juss, Allium cepa L and Aloe vera L., . Aditi, G, Bhandari, B S and Rai, N. 2, 2011, Int. J. PharmTech Res, Vol. 3, pp. 1059-1065.

39. Antifungal activities and chemical characterization of Neem leaf extracts on the growth of some selected fungal 
species in vitro culture medium. Mondali, N K, et al. 1, 2009, Journal of Applied Sciences and Environmental Management, Vol. 13, pp. 49-53.

40. Antifungal activity of leaf extract of neem (Azadirachta indica Linn). Shrivastava, D K and Swarnkar, K. 5, 2014, International Journal of Current Microbiology and Applied Sciences, Vol. 3, pp. 305-308.

41. 'In vitro' anti-viralactivity of neem (Azadirachta indica. A. Juss) leaf extract against group B coxsackieviruses. Badam, L, Joshi, S P and Bedekar, S S. 2, 1999, Journal of Communicable Diseases, Vol. 31, pp. 79-90.

42. A comparative study of the anti-inflammatory effect of aqueous extract of neem leaf and dexamethasone. Mosaddek, A S M and Rashid, M M U. 1, 2008, Bangladesh Journal of Pharmacology, Vol. 3, pp. 44-47.

43. "Antioxidant activity and quantitative estimation of azadirachtin and nimbin in Azadirachta indica A. Juss grown in foothills of Nepal. Ghimeray, A. K., et al. 13, 2009, African Journal of Biotechnology, Vol. 8, pp. 3084-91.

44. "Evaluation of antioxidant activity of flower and seed oil of Azadirachta indica A. juss. Nahak, G and Sahu, R K. 1, 2011, Journal of Applied and Natural Science, Vol. 3, pp. 78-81.

45. Antidiabetic properties of Azardiracta indica and Bougainvillea spectabilis: In vivo studies in murine diabetes model. Bhat, M, et al. 2011, Evidence-Based Complementary and Alternative Medicine, Vol. 2011, pp. 1-9.

46. Comparative Studies on Antidiabetic effect with phytochemical screening of Azadirachta indicia and Andrographis paniculata. Akter, R, et al. 2, 2013, Journal of Pharmacy and Biological Sciences, Vol. 5, pp. 122-28.

47. Antimalarial effect of Neem leaf and Neem stem bark extracts on plasmodium berghei infected in the pathology and treatment of malaria. Akin-Osanaiye, B C, et al. 1, 2013, International Journal of Research in Biochemistry and Biophysics, Vol. 3, pp. 7-14.

48. An antimalarial neem leaf extract has both schizonticidal and gametocytocidal activities. Udeinya, J I, et al. 2, 2008, American Journal of Therapeutics, Vol. 15, pp. 108-110.

49. Immunomodulatory and growth promoting effects of neem leaves infusion in broiler chicks. Durrani, E R, et al. 2008, Sarhad Journal of Agriculture, Vol. 24, pp. 316-321.

50. "Immunopotentiating effects of Azadirachta indica (Neem) dry leaves powder in broilers, naturally infected with $I B D$ virus. Sadekar, R D, et al. 11, 1998, Indian Journal of Experimental Biology, Vol. 36, pp. 1151-53.

51. Evaluation of the wound healing activity of methanolic extract of Azadirachta Indica (Neem) and Tinospora cordifolia (Guduchi) in rats. Barua, C C, et al. 2010, Pharmacologyonline, Vol. 1, pp. 70-77.

52. The wound healing effects of aqueous leave extracts of azadirachta indica on wistar rats. Emeka, A Osunwoke, et al. 6, 2013, Journal of Natural Science and Research,, Vol. 3, pp. 181-86.

53. Nimbolide a limonoid from Azadirachta indica inhibits proliferation and induces apoptosis of human choriocarcinoma (BeWo) cells. Kumar, G Harish, et al. 3, 2009, Investigational New Drugs, Vol. 27, pp. 246-252.

54. The neem limonoids azadirachtinThe neem limonoids azadirachtin in an animal model of oral oncogenesis. Kumar, G H, et al. 4, 2010, Investigational New Drugs , Vol. 28, pp. 392-401.

55. Neem leaf extract inhibits mammary carcinogenesis by altering cell proliferation, apoptosis, and angiogenesis. Arumugam, A, et al. 1, 2104, Cancer Biology and Therapy, Vol. 15, pp. 26-34.

56. To evaluate the antigingivitis and antipalque effect of an Azadirachta indica (neem) mouthrinse on plaque induced gingivitis: a double blind, randomized, controlled trial. Chatterjee, A, et al. 4, 2011, Journal of Indian Society of Periodontology, Vol. 15, pp. 398-401.

57. The inhibiting effect of Azadirachta indica against dental pathogens. Lekshmi, N C J P, et al. 1, 2012, Asian Journal of Plant Science and Research, Vol. 2, pp. 6-10.

58. Hepatoprotective activity of the neem-based constituent azadirachtin-A in carbon tetrachloride intoxicated Wistar rats. Baligar, N S, et al. 4, 2014, Canadian Journal of Physiology and Pharmacology, Vol. 92, pp. 267-77.

59. "Effect of Azadirachta indica (neem) leaf aqueous extract on paracetamol induced liver damage in rats. Bhanwra, S. 1, 2000, Indian Journal of Physiology and Pharmacology, Vol. 44, pp. 64-68.

60. "Gastroprotective effect of aqueous extract of neem Azadirachta indica on induced gastric lesion in rats. Ofusori, D A, et al. 2010, International Journal of Biological and Medical Research, Vol. 1, pp. 219-22.

61. Azadirachta indica attenuates cisplatin induced neurotoxicity in rats. Moneim, A E A. 3, 2014, Indian Journal of Pharmacology, Vol. 46, pp. 316-321. 
62. Azadirachta indica attenuates cisplatin-induced nephrotoxicity and oxidative stress. Moneim, A E A, Othman, M S and Aref, A M. 2014, BioMed Research International, Vol. 2014, pp. 1-11.
63. Wound healing Potential of Mellia azedarach L. leaves in Alloxan induced Diabetic Rats. Vidya, V, Srinivasan, D and Sengottuvelu, S. 7, 2012, Global Journal of Research on Medicinal Plants \& Indeginous Medicine, Vol. 1, pp. 265-71. 